\title{
Electromagnetic and acoustic radiations before Kamchatka earthquake
}

\author{
Yuriy Marapulets ${ }^{1, *}$, Gennadiy Druzhin ${ }^{1}$, Nina Cherneva, and Alexsandra Solodchuk ${ }^{1}$ \\ ${ }^{1}$ Institute of Cosmophysical Research and Radio Wave Propagation FEB RAS
}

\begin{abstract}
The most probable cause of simultaneous anomalous radiations in electromagnetic and acoustic fields, different in nature, is intensification of deformation processes during strong earthquake preparation. To verify this fact, simultaneous observations of electromagnetic signals and acoustic emission in the frequency range from $0.1 \mathrm{~Hz}$ to $11 \mathrm{kHz}$ were carried out in Kamchatka. In the result of the experiment, radiation bursts appeared about 24 hours before a seismic event with $\mathrm{MLH}=5.4$. Such bursts were not observed on other days within this time of a day in August-September, 2013.
\end{abstract}

\section{Introduction}

Investigation of acoustic and electromagnetic fields during increased seismic activity were carried out in different regions [1,2], however, there are just a few simultaneous observations in natural conditions. The authors know only some cases of registration of anomalous radiations of these fields before seismic events with MLH $\geq 5$ [3]. In the laboratory research [4] it was registered that during rock deformation stress, acoustic and electromagnetic radiations are generated. To detect natural electromagnetic and acoustic emissions assuming common deformation nature of their occurrence, simultaneous observations of these fields were carried out in the seismically active region of Kamchatka peninsular in August-September, 2013.

Observations of electromagnetic field variations were carried out at «Karymshina» site $(52.82 \mathrm{~N}, 158.13 \mathrm{E})$. Noise radiations were registered by a multichannel VLF-detector applying magnetic and electric antennas. The signals were recorded in a digital form. The sensitivity of VLF-detector magnetic component was not less than $2.10-7 \mathrm{nT} / \mathrm{Hz}^{1} / 2$, and that of electric component was not less than $6.10-8 \mathrm{~V} /\left(\mathrm{mHz}^{1 / 2}\right)$.

We should note that the main noise sources of natural electromagnetic radiations in the North-East of Russia [5] are world lightning centers located in the near-equatorial region of the Earth.

Signals from the regional lightning were registered by VLF-detector at «Paratunka» site $(52.97 \mathrm{~N}, 158.25 \mathrm{E})$, located at the distance of $18 \mathrm{~km}$ from «Karymshina» site when the threshold level of $1 \mathrm{~V} / \mathrm{m}$ was exceeded [6].

\footnotetext{
*Corresponding author: marpl@ikir.ru
} 
To register the acoustic emission, a complex based on a piezoceramic receiver (hydrophone) was used. It is installed at «Mikizha» site $(52.99 \mathrm{~N}, 158.23 \mathrm{E})$ at the distance of $20 \mathrm{~km}$ from «Karymshina» site by the bottom of a lake [7]. The sensitivity of the hydrophone together with the pre-amplifier is the first hundreds of $\mathrm{mV} / \mathrm{Pa}$. The results of investigation of the acoustic emission in Kamchatka showed that acoustic radiation increase in the high-frequency range from hundreds of $\mathrm{Hz}$ to the first tens of $\mathrm{kHz}$ is determined by the intensification of rock deformations in the observation area including those associated with earthquake preparation [8]. Thus, high-frequency acoustic emission can be applied as a sensitive indicator of intensification of the deformation processes preceding seismic events $[8,9]$.

\section{Detection of anomalies during electromagnetic and acoustic observation analysis}

In the course of data analysis it was discovered that radiation bursts almost simultaneously occurred in electromagnetic and acoustic fields in the frequency range from $200 \mathrm{~Hz}$ to 11 $\mathrm{kHz}$ (Fig. 1, at the bottom) on September 1, 2013 between 04:00 and 09:00 UT at «Karymshina» and «Mikizha» sites. Such bursts were not observed on other days within the same period of a day. Azimuthal distribution of lightning strokes showed (Fig. 1, at the top), that their number increased significantly from the south-western direction $(\sim 2000-$ $2400)$. There were also radiations from the eastern direction $(\sim 450-1350)$. It was assumed that the increased radiations were, probably, associated with deformation processes in the Earth crust. But there were doubts that the detected bursts are associated only with the intensification of lightning activity.

To determine the real cause of anomaly occurrence, noise radiations registered at «Karymshina» site were compared with the direction-finding data obtained at «Paratunka» site and with the data of the World Wide Lightning Location Network (WWLLN) [http://wwlln.com]. An on-line Earthquake Catalogue of Kamchatka Branch of Geophysical Service RAS [http://www.emsd.ru] was also considered.

Fig. 2 shows the direction-finding observations at «Paratunka» site. Vertical lines mark the «anomalous» period which coincides with that in Fig. 1. It is clear from the graphs that the increased level of radiations is observed from the direction of $1800-2700$. Lightning locations from August 31 to September 2, 2013 were determined by WWLLN (Fig. 3).

In order to check the reliability of the determined directions to the radiation sources, the real azimuths of «Alfa» radio station working at the frequencies of 11.90, 12.65 and 14.88 $\mathrm{kHz}$ were compared with those obtained during signal reception at «Karymshina» and «Paratunka» sites. The error did not exceed 3 degrees. Moreover, we also used the lightning sources registered by WWLLN, including the lightning source near Kluchevskaya sopka and Siveluch volcanoes which was observed on August 31, 2013 (Fig. 3). 


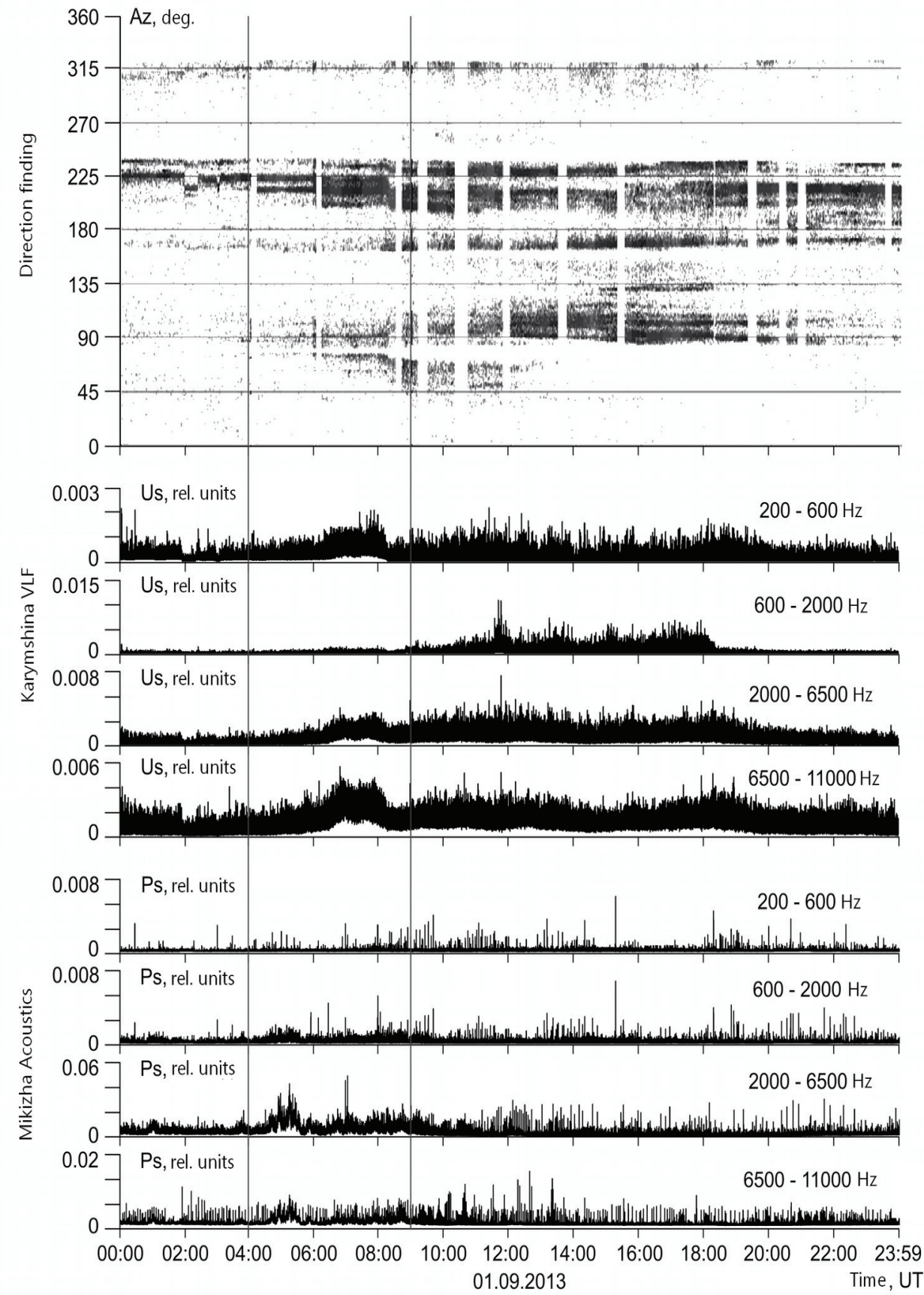

Fig. 1. Simultaneous observations of acoustic and electromagnetic radiations on September 1, 2013 at «Karymshina» (VLF) and «Mikizha» (acoustics) sites. In the upper part of the figure is the azimuthal distribution of lightning stroke number AZ (dots) within a day. The azimuth for «Karymshina» site is counted clockwise from the northern direction. In the bottom part of the figure are the amplitude variations of the envelope of VLF-radiation US acoustic emission PS, in four frequency sub-ranges. Vertical lines indicate the time interval from 4:00 till 9:00 UT, within which anomalous bursts of radiation were recorded. 
$A z$, deg.

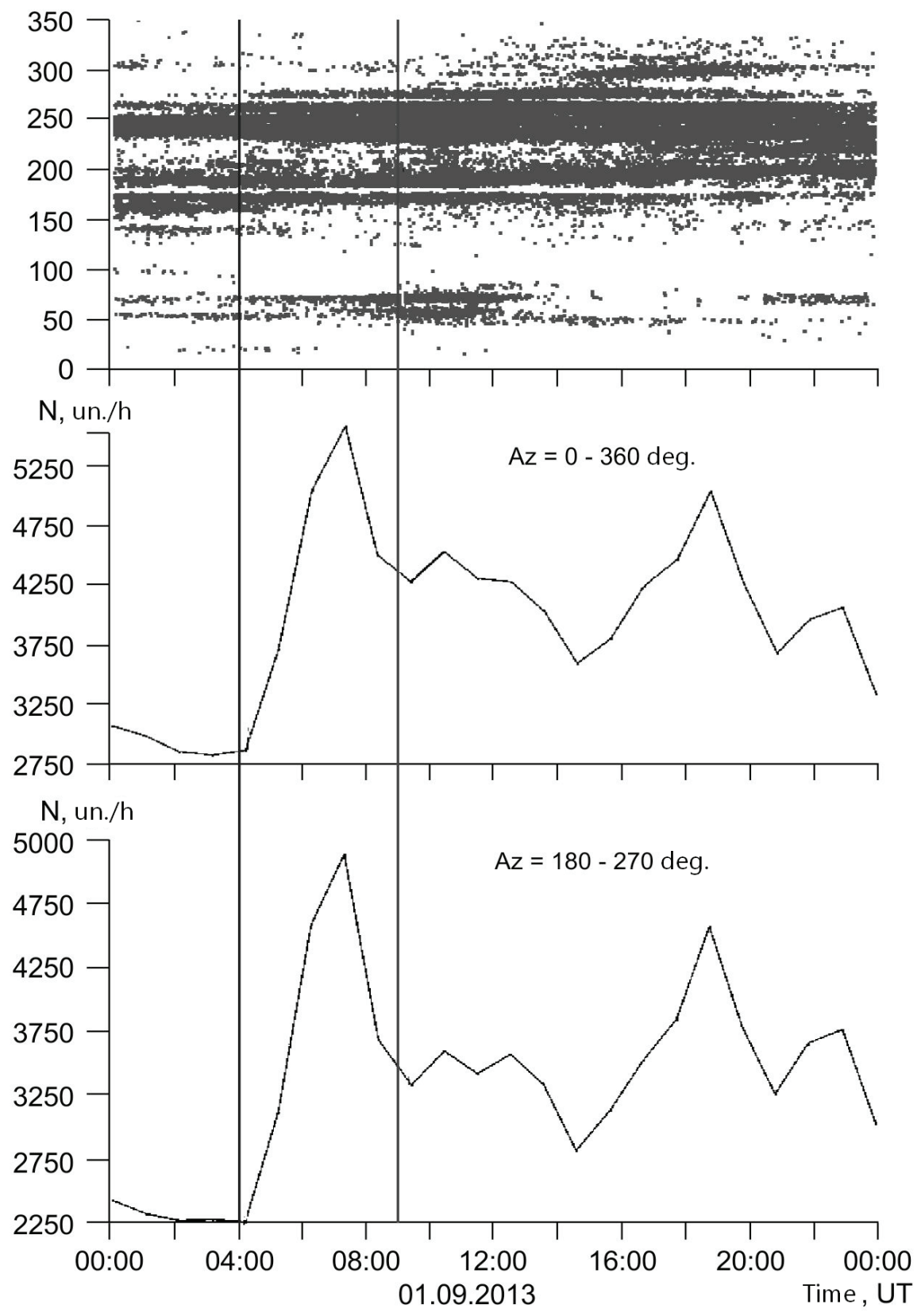

Fig. 2. Direction-finding observations of electromagnetic radiations on September 1, 2013 at «Paratunka» site. Azimuthal distribution of the sources registered at «Paratunka» site is shown in the upper part of the figure. Hourly numbers of lightning strokes the radiations from which were received from the directions of $0-360$ degrees and $180-270$ degrees are in the bottom. Vertical lines indicate the radiation area from 4:00 to 9:00 UT. 

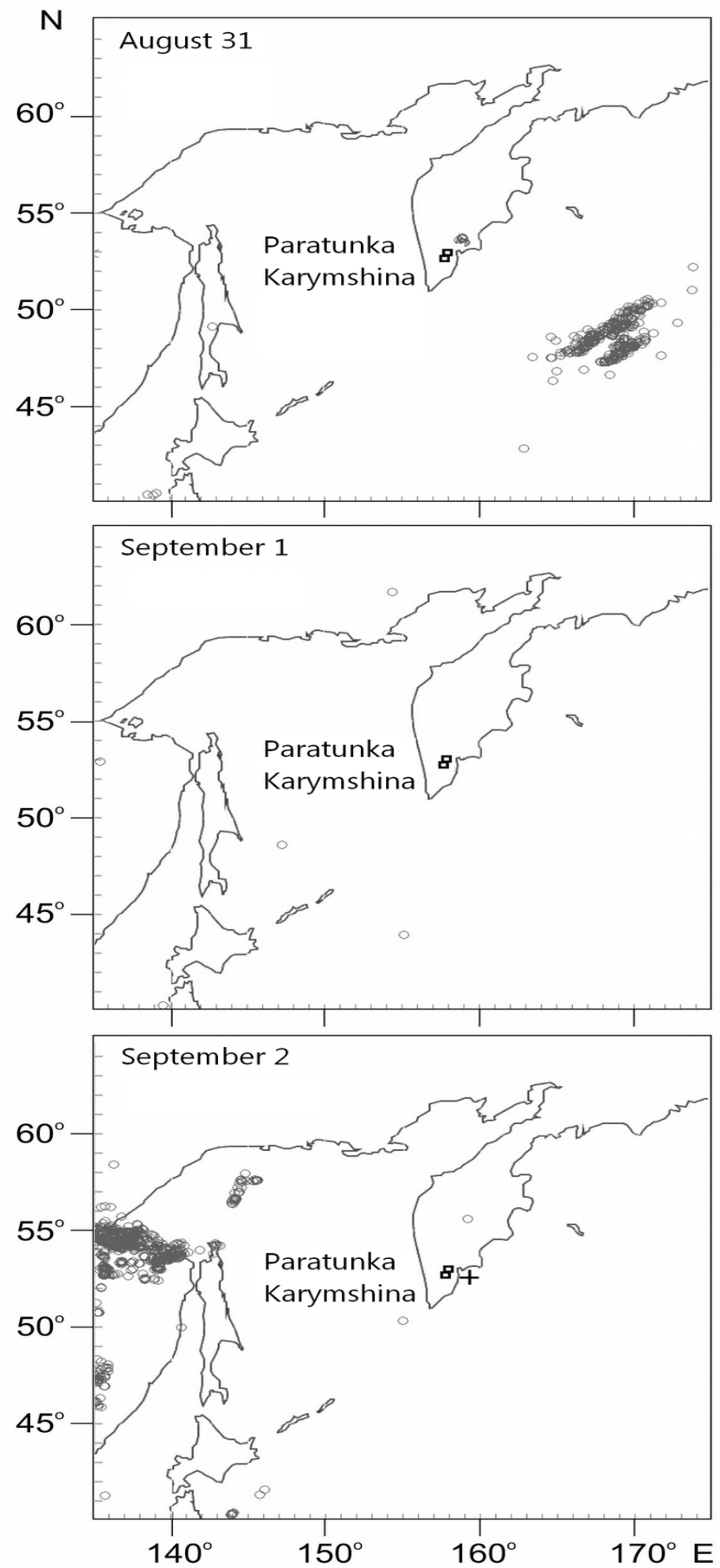

Fig. 3. A map with lightning strokes (circles) which occurred near Kamchatka from August 31 to September 2 and the earthquake $(+)$ which occurred on September 2, 2013. Site locations are indicated by squares. 
It is clear from Fig. 3 that lightning activity was quite high on August 31, on September 1 (during the anomaly) the lightning was not almost observed, and on September 2 it appeared again. The inconsistency of the number of received signals from lightning by WWLLN network and «Karymshina» and «Paratunka» sites is explained by the difference in instrumentation and radiation registration methods. It was established by the researches which had been carried out before [6] that in spite of the indicated differences, quite good agreement of the data was observed when lightning azimuths were determined. Thus, during the period of observation of anomalous bursts on September 1, there was no strong lightning.

It is quite possible that some local radiation sources appeared, the power of which is sufficient to be detected by closely located electromagnetic sensors located at «Karymshina» and «Paratunka» sites but insufficient to be registered by remote sensors of WWLLN network due to signal strong attenuation.

\section{Discussion of the obtained results}

Based on the data of the on-line earthquake catalogue, analysis of the seismic state revealed that the earthquake with the energy class of $\mathrm{K}=12.3$ ( $\mathrm{MLH}=5.1$ ) occurred on September 2, 2013 at 8:19 UT, that is about one day after the anomalous radiations, at the epicentral distance of $140 \mathrm{~km}$ from «Karymshina» site. For the earthquake energy classification, we used classes K according to S.A. Fedotov's scale [10]. The relation of K to magnitude MLH is determined by formula $\mathrm{MLH}=(\mathrm{K}-4.6) / 1.5)$. We should note that this was the only earthquake with $\mathrm{MLH} \geq 5$, which occurred in the first half of September in the south-eastern part of Kamchatka.

Taking into account all the abovesaid, the following scenarios of anomalous acoustic and electromagnetic radiations are the most probabilistic:

1. A powerful remote source (not associated with the seismic event) became active. The radiation from it came from the south-western direction, in the result, VLF signal level increased during the time period indicated by the vertical lines shown in Fig. 1 and Fig. 2. But in this case, the cause of acoustic emission anomalies is unclear (Fig. 1).

2. Remote source activity changed insignificantly but in the result of deformation processes, the propagation conditions changed (for example, the Earth's crust conductivity near the observation site changed) that caused intensification of the signals received from lightning. This fact may take place since considerable increase of electromagnetic field pulse flux was observed near the Earth crust fractures [11].

3. A closely located source of electromangetic radiation, associated with deformation processes in the earth crust, appeared. This scenario is quite possible as long as radiations were observed at the same time both in acoustic and electromagnetic fields.

Simultaneous anomalies of acoustic and electromagnetic radiations are often registered 1-2 days before quite strong earthquakes in Kamchatka. Based on the on-line earthquake catalogue, 11 seismic events with MLH $\geq 5$ occurred at the hypocentral distances up to 200 $\mathrm{km}$ from «Karymshina» site in 2013. From them, except for the case described above, radiation bursts were recorded before 6 seismic events (Table) that results in $63.6 \%$ from all the earthquakes with MLH $\geq 5$. Examples of anomalies are shown in Fig. 4. 
Table. Simultaneous anomalies of acoustic and electromagnetic radiations before earthquakes with $\mathrm{MLH} \geq 5$.

\begin{tabular}{|c|c|c|c|}
\hline No. & $\begin{array}{c}\text { Anomaly } \\
\text { duration, hours }\end{array}$ & $\begin{array}{c}\text { Earthquake advance } \\
\text { time, hours }\end{array}$ & Earthquake data, date, time, $\mathbf{M}_{\mathbf{L H}}$ \\
\hline 1 & 3.8 & 38.6 & $09.03 .13,14: 56 \mathrm{UT}, \mathrm{M}_{\mathrm{LH}}=6.0$ \\
\hline 2 & 2.9 & 22.8 & $03.05 .13,06: 10 \mathrm{UT}, \mathrm{M}_{\mathrm{LH}}=5.6$ \\
\hline 3 & 7.2 & 30.6 & $28.05 .13,16: 25 \mathrm{UT}, \mathrm{M}_{\mathrm{LH}}=5.4$ \\
\hline 4 & 5.0 & 33.5 & $15.07 .13,14: 43 \mathrm{UT}, \mathrm{M}_{\mathrm{LH}}=5.6$ \\
\hline 5 & 0.9 & 23.8 & $28.07 .13,07: 21 \mathrm{UT}, \mathrm{M}_{\mathrm{LH}}=5.3$ \\
\hline 6 & 3.0 & 29.8 & $21.09 .13,06: 58 \mathrm{UT}, \mathrm{M}_{\mathrm{LH}}=5.4$ \\
\hline
\end{tabular}

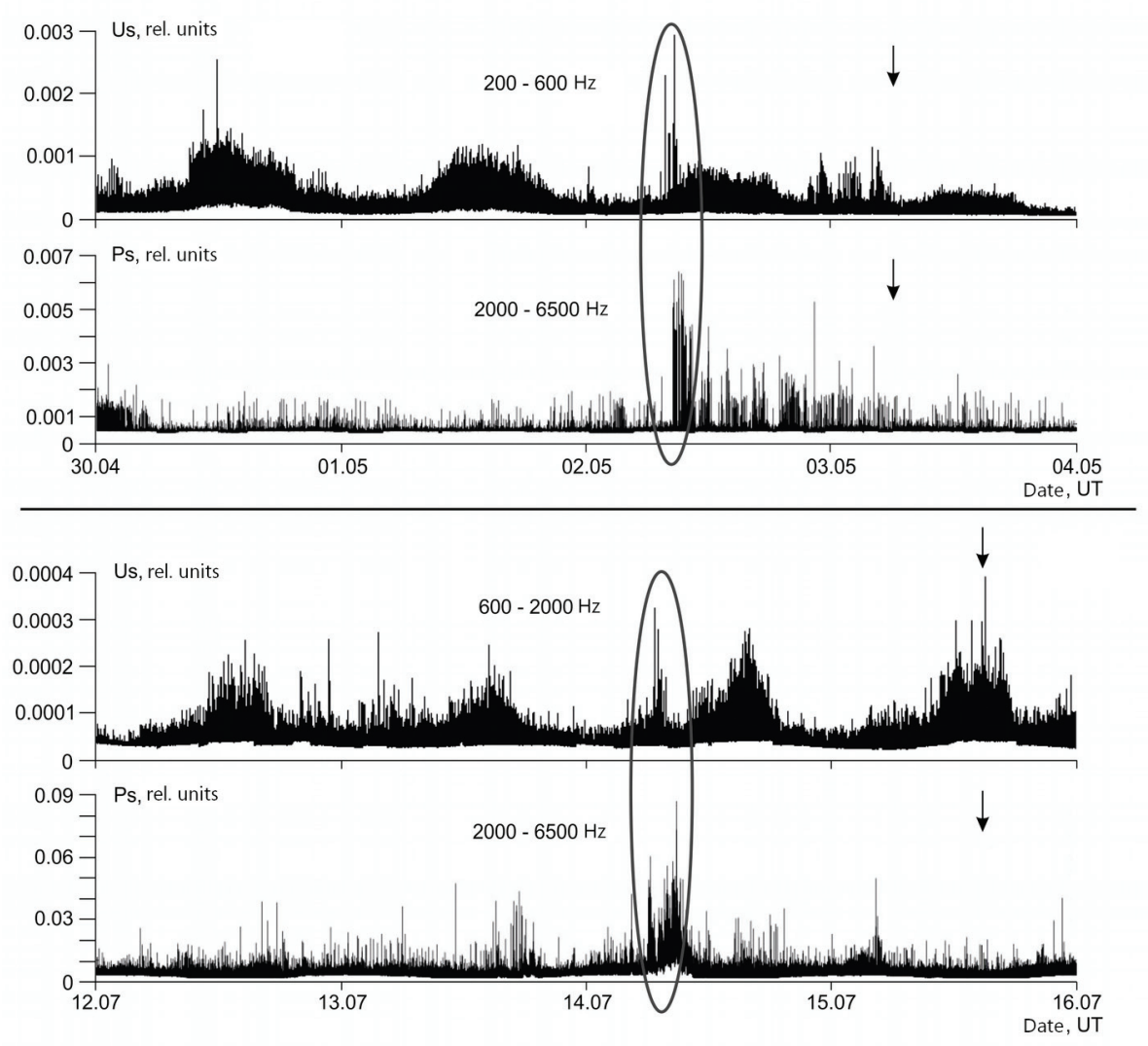

Fig. 4. Simultaneous observations of electromagnetic (US) and acoustic (PS) radiations before earthquakes on May 3 (at the top) and on July 14 (at the bottom). Anomalous bursts of radiations are marked by ellipses. Arrows indicate the earthquake times.

\section{Conclusions}

Thus, in the result of observations of acoustic and electromagnetic fields in 2013, it was discovered that more than a half of seismic events with $\mathrm{MLH} \geq 5$ at the hypocentral distance 
up to $200 \mathrm{~km}$ are proceeded within 1-2 day interval by simultaneous bursts of acoustic and electromagnetic radiations in the frequency range from $200 \mathrm{~Hz}$ to $11 \mathrm{kHz}$. To the author's opinion, the most probable reason of occurrence of anomalous radiations in the fields different in nature is the intensification of deformation processes during earthquake preparation.

\section{References}

1. B.M. Gokhberg, V.A. Morgunov, O.A. Pokhotelov, [Seismoelectromagnetic phenomena] (Nauka, Moscow, 1988) 174 p.

2. M.A. Sadovskiy, [Electromagnetic precursors of earthquakes] (Nauka, Moscow, 1988) $89 \mathrm{p}$.

3. V.A. Gavrilov, Doklady Earth Sciences, 414(1), 638-641 (2007)

4. Y. Mori, Y. Obata and J. Sikula, Acoustic Emission, 27, 157-166 (2009)

5. G.I. Drugin, V.I. Shapaev, Geomagnetism and Aeronomy, 28(1), 81-86 (1988)

6. G.I. Drugin, N.V. Cherneva, A.N. Melnikov, Russian Meteorology and Hydrology, 36(7), 447-452 (2011)

7. A.V. Kuptsov, Izvestiya, Physics of the Solid Earth, 41(10), 825-831 (2005)

8. G.I. Dolgih, A.V. Kuptsov, I.A. Larionov, et. al., Doklady Earth Sciences, 413(1), 281285 (2007)

9. Yu.V. Marapulets, B.M. Shevtsov, I.A. Larionov et. al., Russian Journal of Pacific Geology, 6(6), 457-464 (2012)

10. S.A. Fedotov, [Energy classification of the Kuril-Kamchatka earthquakes and the problem of magnitudes] (Nauka, Moscow, 1972) $116 \mathrm{p}$.

11. E.L. Afraymovich, G.A. Zherebtsov, [Seismoionospheric and seismoelectromagnetic processes in the Baikal rift zone] (SB RAS, Novosibirsk, 2012) 304 p. 